\title{
Analisis Kestabilan Model Eko-Epidemiologi dengan Pemanenan Konstan pada Predator
}

\author{
Nurhalis Hasan $^{1^{*}}$, Resmawan $^{2 *}$, Emli Rahmi $^{3 *}$
}

\begin{abstract}
The main purpose of this research is to study the stability analysis of the eco-epidemiology model with constant harvesting to predator. The population of this model divided into three sub population those are susceptible prey $x_{S}$, infected prey $x_{I}$, and predator $y$. The eco-epidemiology model is constructed by given harvesting to predator. Two equilibrium points were obtained, the equilibrium point of infected prey extinction, and the interior equilibrium points where the three sub population exist. The existence of each equilibrium points depend on $y^{*}$. The Jacobi matrix is determined before the stability of the model is studied. Each stability of the equilibrium points described on its stability condition of each equilibrium points. Numerical simulation is done to distinct the stability of the equilibrium points. The numerical simulation is done by using 4th-order Runge-Kutta method and Phyton 3.7.
\end{abstract}

Keywords: Model Eco-Epidemiological, equilibrium point, Jacobi Matrix, Stability, Numerical Simulation

\begin{abstract}
Abstrak
Penelitian ini dilakukan untuk menganalisis kestabilan model eko-epidemiologi dengan pemanenan konstan terhadap predator. Populasi dalam model terbagi atas tiga populasi yaitu populasi prey rentan $\mathrm{x}_{\mathrm{S}}$, populasi prey terinfeksi $\mathrm{x}_{\mathrm{I}}$, dan populasi predator $\mathrm{y}$. Dikonstruksi model eko-epidemiologi dengan pemanenan konstan terhadap predator. Diperoleh dua titik kesetimbangan, yaitu titik kesetimbangan kepunahan populasi prey terinfeksi, dan titik kesetimbangan interior atau semua populasi ada. Eksistensi dari masing-masing titik kesetimbangan bergantung pada $\mathrm{y}^{*}$ atau akar-akar realnya masingmasing. Sebelum mencari kestabilan dari titik-titk kestimbangan, ditentukan terlebih dahulu matriks Jacobi. Kestabilan dari masing-masing titik diuraikan pada syarat kestabilannya masing-masing. Simulasi numerik dari titik kesetimbangan dilakukan agar terlihat lebih jelas kestabilan dari masing-masing titik kesetimbangan. Simulasi numerik dilakukan menggunakan metode Runge-Kutta orde 4 dan dibantu software Phyton 3.7.
\end{abstract}

Kata kunci: Model Eko-Epidemiologi, Ttitik Kesetimbangan, Matriks Jacobi, Kestabilan, Simulasi Numerik.

\section{Pendahuluan}

Pada pemodelan matematika predasi (predatorisme) yang merupakan hubungan antara pemangsa (predator) dengan mangsa (prey), diubah ke dalam bentuk suatu sistem persamaan yang disebut sistem predator-prey untuk dipelajari dinamika populasinya. Pada tahun 1798, Thomas Malthus mengusulkan teori populasi dinamis dengan mengasumsikan populasi bertumbuh secara eksponensial atau bisa dikatakan tumbuh tanpa batas. Setelahnya, tahun 1838 Verhulst mengembangkan teori dari Malthus dengan mengasumsikan bahwa suatu populasi akan tumbuh secara logistik atau bisa dikatakan suatu populasi tidak akan tumbuh melewati batas pertumbuhan populasi yang ditentukan. Pada tahun 1925-1928 terjadi

*Program Studi Matematika, Jurusan Matematika FMIPA Universitas Negeri Gorontalo

Email: nurhalishasan21@gmail.com, resmawan@ung.ac.id",emlirahmi@ung.ac.id 
kemajuan besar dalam teori yang mempelajari pertumbuhan populasi yang dilakukan oleh Lotka 1925 dan Voltera 1928 dengan memperoleh persamaan logistik, yang mana disebut "hukum pertumbuhan populasi", serta mengusulkan pertamakali model populasi dua spesies yaitu model predator-prey dengan asumsi pertumbuhan prey mengikuti model Malthus. Tahun 1934, Gause mengembangkan model Lotka-Voltera dengan menerapkan asumsi pertumbuhan logistik pada prey [1].

Dalam pengembangan model predator-prey Holling pada tahun 1959 melakukan pendekatan analitik terhadap model prdator-prey dengan menambahkan komponen dasar fungsi respon. Holling memperkenalkan tiga fungsi respon, yaitu respon tipe $I$, respon tipe $I I$, dan respon tipe III [2]. Selain itu, topik lain yang muncul dalam ekologi adalah pemanenan yang dapat berfungsi untuk mengontrol suatu populasi, yang mana pemanenan yang sering dipelajari dalam pemodelan matematika adalah pemanenan konstan, pemanenan proposional, dan pemanenan nonlinear. Dalam bidang ekologi, penyebaran penyakit dapat terjadi dalam interaksi antar komponen-komponen penyusunnya. Untuk mempelajari penyebaran penyakit yang menular pada setiap spesies yang saling berinteraksi, diintegrasikan bidang ilmu ekologi dan epidemiologi sehingga membentuk bidang ilmu eko-epidemiologi. Faktor penyakit pada sistem predator-prey diperkenalkan pertamakali oleh Anderson dan Mei [3] yang meneliti faktor suatu gangguan yang terjadi pada sistem persamaan interaksi predator-prey dan menemukan studi kasus faktor pengendalian penyakit pada sistem persamaan predator-prey.

Fenomena alam yang memperlihatkan interaksi antara predator dan prey, dimana populasi prey terserang penyakit dijelaskan oleh Chattopadhyay dan Bairagi [4]. Pada model ini diasumsikan populasi prey terinfeksi oleh penyakit dan ditambahkan faktor pemanenan pada populasi prey. Selain itu, interaksi antara predator dan prey, dimana populasi prey terserang penyakit dijelaskan oleh Purnomo dkk [5]. Model ini diasumsikan populasi prey terinfeksi oleh penyakit, ditambahkan faktor pemanenan proporsional pada populasi prey rentan, predator dapat menentukan prey rentan dan prey terinfeksi, predator hanya memangsa prey terinfeksi mengikuti fungsi respon Holling tipe II. Model predator-prey dimana pemanenan pada suatu populasi di panen secara konstan dijelaskan oleh Jha PK dan Ghorai S [6]. Model ini diasumsikan populasi prey tumbuh secar logistik, pemangsaan mengikuti fungsi respon Holling tipe II, terdapat kematian alami pada populasi predator, dan dilakukan pemanenan secara konstan terhadap populasi prey.

Pada artikel ini dibahas model matematika eko-epidemiologi dengan menggunakan model predator-prey Holling tipe I, dengan populasi prey terinfeksi penyakit. Selain itu diasumsikan adanya pemanenan secara konstan pada populasi predator. Hal ini dikarenakan peneliti akan meneliti suatu interaksi antara predator dan prey yang mana populasi prey terinfeksi oleh penyakit, dan populasi predator memiliki sifat pasif atau lebih suka menunggu mangsanya (prey) serta populasi predator merupakan populasi yang dapat dipanen.

\section{Model Matematika}

Model eko-epidemiologi dengan pemanenan konstan yang dibahas pada artikel ini diintegrasikan dari model predator-prey tipe Gause dan model epidemi SI. Pada model ini yang terinfeksi oleh penyakit adalah populasi prey, sehingga populasi prey terbagi menjadi dua kelas yaitu, populasi prey rentan yang dinotasikan $x_{S}$ dan populasi prey terinfeksi yang dinotasikan $x_{I}$. Fungsi respon yang digunakan pada model ini merupakan fungsi respon Holling tipe $I$, dimana predator yang dinotasikan $y$ memiliki sifat pasif atau lebih suka menunggu prey. Predator merupakan poulasi yang dapat dipanen, sehingga pada model ini pemanenan pada predator dilakukan dengan ukuran $Q_{y}$ yang sama. Dari asumsi-asumsi yang ada model eko-epidemiologi dengan pemanenan konstan terhadap predator dapat di modelkan yang disajikan pada persamaan (1). 


$$
\begin{aligned}
& x_{S}=r x_{S}\left(1-\left(\frac{x_{S}+x_{I}}{K}\right)\right)-m_{1} x_{S} y-a x_{S} x_{I} \\
& x_{I}=a x_{S} x_{I}-m_{2} x_{I} y-c_{1} x_{I} \\
& y=b_{1} x_{S} y+b_{2} x_{I} y-c_{2} y-Q_{y}
\end{aligned}
$$

dimana $r, K, m_{1}, m_{2}, b_{1}, b_{2}, a, c_{1}, c_{2}$, dan $Q_{y}$ masing-masing adalah laju pertumbuhan intrinsik populasi prey rentan, daya dukung lingkungan hidup populasi, laju pemangsaan predator terhadap mangsanya prey rentan, laju pemangsaan predator terhadap mangsanya prey terinfeksi, jumlah populasi predator yang masuk akibat memangsa prey rentan, jumlah populasi predator yang masuk akibat memangsa prey terinfeksi, laju interaksi antara populasi prey rentan dan prey terinfeksi, kematian alami prey terinfeksi, kematian alami predator, dan jumlah panen.

Untuk mempermudah proses analisis model, dilakukan penskalaan terlebih dahulu pada model (1). Menurut Edelstein-Keshet [7], penskalaan model akan memangkas beberapa parameter sehingga dapat merubah model secara kuantitif tetapi tidak secara kualitatif. Dengan melakukan penskalaan $\left(x_{S}, x_{I}, y, t\right) \rightarrow\left(\frac{x_{S}}{K}, \frac{x_{I}}{K}, \frac{m_{1}}{r} y, r t\right)$ model (1), sehingga sistem tereduksi menjadi:

$$
\begin{aligned}
& x_{S}=x_{S}\left(1-x_{S}-x_{I}\right)-x_{S} y-\beta x_{S} x_{I} \\
& x_{I}=\beta x_{S} x_{I}-\mu x_{I} y-\alpha x_{I} \\
& y=\eta_{1} x_{S} y+\eta_{2} x_{I} y-\delta y-q
\end{aligned}
$$

dengan $\alpha=\frac{c_{1}}{r}, \beta=\frac{a K}{r}, \delta=\frac{c_{2}}{r}, \eta_{1}=\frac{b_{1} K}{r}, \eta_{2}=\frac{b_{2} K}{r}, \mu=\frac{m_{2}}{m_{1}}$, dan $q=\frac{Q_{y} m_{1}}{r^{2}}$.

Parameter yang ada pada model (2) selalu positif. Hal ini didasari oleh kondisi biologis di alam bahwa tidak ada jumlah populasi, pemanenan, ataupun pemangsaan yang negatif. Pada artikel ini, model (2) adalah model yang akan dianalisis kestabilan dari titik kesetimbangan yang diperoleh.

\section{Hasil dan Pembahasan}

\subsection{Titik Kesetimbangan}

Definisi 3.1 Titik $x_{0} \in \mathbb{R}^{\boldsymbol{n}}$ disebut titik kesetimbangan atau titik kritis, jika $f\left(x_{0}\right)=0$. Titik kesetimbangan $x_{0}$ disebut titik kesetimbangan hiperbolik, jika tidak terdapat nilai eigen dari matriks Jacobi $f(x)$ yang memiliki bagian nol real [8].

Berdasarkan Definisi 3.1 titik kesetimbangan model (2) diperoleh dari persamaan berikut.

$$
\begin{aligned}
& \text { (1). } x_{S}=0 \text {, atau } \\
& \text { (2). } 1-x_{S}-x_{I}-y-\beta x_{I}=0 . \\
& \text { (3). } x_{I}=0 \text {, atau } \\
& \text { (4). } \beta x_{S}-\mu y-\alpha=0 . \\
& \text { (5). } \eta_{1} x_{S} y+\eta_{2} x_{I} y-\delta y-q=0 \text {. }
\end{aligned}
$$

yang mana titik kesetimbangan model (2) diperoleh dua titik kesetimbangan, yaitu:

dengan $y_{E_{0}}^{*}$ adalah

$$
E_{0}=\left(1-y_{E_{0}}^{*}, 0, y_{E_{0}}^{*}\right)
$$

$$
\begin{aligned}
& y_{1,2}=\frac{-(o) \pm \sqrt{D y_{E_{0}}^{*}}}{2 \eta_{1}} \\
& D y_{E_{0}}^{*}=(o)^{2}-4 \eta_{1} q
\end{aligned}
$$


dan $o=\delta-\eta_{1}$.

dimana $y_{E_{1}}^{*}$ adalah

$$
E_{1}=\left(\frac{\mu y_{E_{1}}^{*}+\alpha}{\beta}, \frac{\beta-\left(\alpha+(\beta+\mu) y_{E_{1}}^{*}\right)}{\beta(1+\beta)}, y_{E_{1}}^{*}\right)
$$

dengan

$$
\begin{aligned}
& y_{1,2}=\frac{-\left(d_{3}-d_{4}\right) \pm \sqrt{D y_{E_{1}}^{*}}}{2\left(d_{1}-d_{2}\right)} \\
& D y_{E_{1}}^{*}=\left(d_{3}-d_{4}\right)^{2}+4\left(d_{1}-d_{2}\right) q \beta(1+\beta)
\end{aligned}
$$

$$
\begin{aligned}
& d_{1}=\eta_{1} \mu(1+\beta) \\
& d_{2}=\eta_{2}(\mu+\beta) \\
& d_{3}=\eta_{1} \alpha(1+\beta)+\eta_{2} \beta \\
& d_{4}=\eta_{2} \alpha+\delta \beta(1+\beta)
\end{aligned}
$$

\subsection{Eksistensi Titik Kesetimbangan}

Lemma $3.1 \mathbb{R}_{+}^{3}:=(x, y, z) \mid x \geq 0, y \geq 0, z \geq 0,(x, y, z) \in \mathbb{R}$. Misalkan $E_{\boldsymbol{i}}=$ $(\tilde{x}, \tilde{y}, \tilde{z}), i=0,1$ merupakan solusi dari model (2), maka $E_{\boldsymbol{i}}$ adalah titik kesetimbangan dari model (2) jika $E_{\boldsymbol{i}} \in \mathbb{R}$.

\section{Bukti.}

Melihat kondisi biologis di alam, tidak memungkinkan jumlah populasi suatu spesies bernilai negatif, maka solusi dari model (2) harus bernilai positif.

Dengan mengikuti Lemma 3.1 agar setiap titik kesetimbangan yang diperoleh dapat terdefinisi di $\mathbb{R}_{+}^{3}$, maka eksitensi dari setiap titik kesetimbangan yang diperoleh diuraikan dalam beberapa poin berikut:

- Eksistensi titik kesetimbangan $E_{0}$ diuraikan dalam Teorema 4.1.

Teorema $4.1 E_{0} \in \mathbb{R}_{+}^{3} j i k a$

(a). $q<\frac{(o)^{2}}{4 \eta_{1}}, \eta_{1}>\delta$ dan $0<y_{E_{0}}^{*}<1$. Kondisi ini menghasilkan dua titik kesetimbangan $E_{0} \in \mathbb{R}_{+}^{3}$. Atau,

(b). $q=\frac{(o)^{2}}{4 \eta_{1}}, \eta_{1}>\delta$ dan $<0<y_{E_{0}}^{*}<1$. Kondisi ini menghasilkan satu titik kesetimbangan $E_{0} \in \mathbb{R}_{+}^{3}$.

- Eksistensi titik kesetimbangan $E_{1}$ diuraikan dalam Teorema 4.2.

\section{Teorema 4.2}

(a). $E_{1}$ tidak terdapat di $\mathbb{R}_{+}^{3}$ jika $D y_{E_{1}}^{*}<0$. Kondisi ini tidak menghasilkan titik interior.

(b). $E_{1} \in \mathbb{R}_{+}^{3} j i k a D y_{E_{1}}^{*}>0$ dan :

i). $\max \left\{\frac{d_{4}-\eta_{2} \beta}{\alpha(1+\beta)}, \frac{d_{2}}{\mu(1+\beta)}\right\}<\eta_{1}<\frac{d_{4}+\sqrt{D y_{E_{1}}^{*}}-\eta_{2} \beta}{\alpha(1+\beta)}$, dan $\alpha<\beta-(\beta+\mu) y_{E_{1}}^{*}$.

Atau,

ii). $\max \left\{\frac{d_{4}-\eta_{2} \beta}{a(1+\beta)}, \frac{d_{4}-\sqrt{D y_{E_{1}}^{*}}-\eta 2 \beta}{\alpha(1+\beta)}\right\}<\eta_{1}<\frac{d_{2}}{\mu(1+\beta)}$, dan $\alpha<\beta-(\beta+\mu) y_{E_{1}}^{*}$.

Atau,

iii). $\max \left\{\frac{d_{4}-\sqrt{D y_{E_{1}}^{*}}-\eta_{2} \beta}{\alpha(1+\beta)}, \frac{d_{2}}{\mu(1+\beta)}\right\}<\eta_{1}<\frac{d_{4}-\eta_{2} \beta}{a(1+\beta)}$, dan $\alpha<\beta-(\beta+\mu) y_{E_{1}}^{*}$.

Atau, 
iv). $\eta_{1}<\min \left\{\frac{d_{4}-\eta_{2} \beta}{a(1+\beta)}, \frac{d_{4}+\sqrt{D y_{E_{1}}^{*}}-\eta_{2} \beta}{\alpha(1+\beta)}, \frac{d_{2}}{\mu(1+\beta)}\right\}$, dan $\alpha<\beta-(\beta+\mu) y_{E_{1}}^{*}$. Atau,

v). $\max \left\{\frac{d_{4}+\sqrt{D y_{E_{1}}^{*}}-\eta_{2} \beta}{\alpha(1+\beta)}, \frac{d_{2}}{\mu(1+\beta)}\right\}<\eta_{1}<\frac{d_{4}-\eta_{2} \beta}{a(1+\beta)}$, dan $\alpha<\beta-(\beta+\mu) y_{E_{1}}^{*}$.

Kondisi ini menghasilkan dua titik kesetimbangan $E_{1} \in \mathbb{R}_{+}^{3}$.

(c). $E_{1} \in \mathbb{R}_{+}^{3}$ jika $D y_{E_{1}}^{*}=0$ dan :

i). $\frac{d_{4}-\eta_{2} \beta}{a(1+\beta)}<\eta_{1}<\frac{d_{2}}{\mu(1+\beta)}$, dan $\alpha<\beta-(\beta+\mu) y_{E_{1}}^{*}$. Atau,

ii). $\frac{d_{2}}{\mu(1+\beta)}<\eta_{1}<\frac{d_{4}-\eta_{2} \beta}{a(1+\beta)}$, dan $\alpha<\beta-(\beta+\mu) y_{E_{1}}^{*}$.

Kondisi ini menghasilkan satu titik kesetimbangan $E_{1} \in \mathbb{R}_{+}^{3}$.

\subsection{Kestabilan Titik Kesetimbangan}

Untuk mengetahui kestabilan dari titik-titik kesetimbangan model (2), dilakukan pelinieran terhadap model (2) sehingga diperoleh matriks Jacobi yang disajikan pada matriks (3).

$$
J\left(x_{S}, x_{I}, y\right)=\left[\begin{array}{ccc}
1-2 x_{S}-x_{I}-y-\beta x_{I} & -\beta x_{S}-x_{S} & -x_{S} \\
\beta x_{I} & \beta x_{S}-\mu y-\alpha & -\mu x_{I} \\
\eta_{1} y & \eta_{2} y & \eta_{1} x_{S}+\eta_{2} x_{I}-\delta
\end{array}\right]
$$

\subsubsection{Kestabilan Titik Kesetimbangan $E_{0}$}

Dengan mensubtitusikan titik kesetimbangan $E_{0}$ ke matriks (3), diperoleh matriks $J\left(E_{0}\right)$ yang disajikan pada matriks (4).

$$
J\left(x_{S}, x_{I}, y\right)=\left[\begin{array}{ccc}
-\left(1-y_{E_{0}}^{*}\right) & -\beta\left(1-y_{E_{0}}^{*}\right)-\left(1-y_{E_{0}}^{*}\right) & -\left(1-y_{E_{0}}^{*}\right) \\
\beta x_{I} & \beta x_{S}-\mu y-\alpha & -\mu x_{I} \\
\eta_{1} y & \eta_{2} y & \eta_{1} x_{S}+\eta_{2} x_{I}-\delta
\end{array}\right]
$$

Nilai eigen dari $J\left(E_{0}\right)$ diperoleh dari $\operatorname{det}\left(J\left(E_{0}\right)-\lambda I\right)=0$, dimana $I$ adalah matriks identitas $3 \times 3$. Dari $\left.J\left(E_{0}\right)-\lambda I\right)=0$, diperoleh

$$
\begin{gathered}
\lambda_{1}=\beta\left(1-y_{E_{0}}^{*}\right)-\left(\alpha+\mu y_{E_{0}}^{*}\right) \\
\text { dan } \\
\lambda^{2}+\left(g_{1}-g_{2}\right) \lambda+\left(g_{3}-g_{4}\right)=0
\end{gathered}
$$

dimana

$$
\begin{aligned}
& g_{1}=\left(1-y_{E_{0}}^{*}\right)+\mu y_{E_{0}}^{*}+\alpha \\
& g_{2}=\beta\left(1-y_{E_{0}}^{*}\right) \\
& g_{3}=\left(1-y_{E_{0}}^{*}\right) \mu y_{E_{0}}^{*}+\alpha\left(1-y_{E_{0}}^{*}\right)+\left(1-y_{E_{0}}^{*}\right) \eta_{1} y_{E_{0}}^{*} \\
& g_{4}=\beta\left(1-y_{E_{0}}^{*}\right)^{2}
\end{aligned}
$$

Kestabilan dari $E_{0}$ dijelaskan dalam Teorema 4.3

Teorema 4.3 Titik kesetimbangan $E_{0}$ stabil atau stabil asimptotik lokal, jika $\beta<\frac{\alpha+\mu y_{E_{0}}^{*}}{1-y_{E_{0}}^{*}}$, $k_{0}>0, g_{1}>g_{2}$, dan $g_{3}>g_{4}$. Sebaliknya, jika syarat stabil tidak terpenuhi maka titik 
kesetimbangan $E_{0}$ tidak stabil untuk semua syarat stabil tidak terpenuhi, atau tidak stabil saddle untuk salah satu syarat stabil tidak terpenuhi.

\subsubsection{Kestabilan Titik Kesetimbangan $E_{1}$}

Sebelum mencari persamaan linearisasi titik kesetimbangan $E_{1}$, terlebih dahulu disederhanakan matriks Jacobi (3) agar memudahkan proses pencarian persamaan linearisasi $E_{1}$. Untuk menyederhanakan matriks Jacobi (3), lihat persamaan yang memperoleh titik kesetimbangan $E_{1}$, sehingga matriks Jacobi (3) menjadi matriks Jacobi $J\left(x_{S}, x_{I}, y\right)^{*}$ yang disajikan pada matriks (5)

$$
J\left(x_{S}, x_{I}, y\right)^{*}=\left[\begin{array}{ccc}
-x_{S} & -\beta x_{S}-x_{S} & -x_{S} \\
\beta x_{I} & 0 & -\mu x_{I} \\
\eta_{1} y & \eta_{2} y & \frac{q}{y}
\end{array}\right]
$$

dengan mensubtitusikan titik kesetimbangan $E_{1}$ ke matriks $J\left(x_{S}, x_{I}, y\right)^{*}$, diperoleh matriks $J\left(E_{1}\right)^{*}$ yang dapat dituliskan.

$J\left(E_{1}\right)^{*}=$

$$
\left[\begin{array}{ccc}
-\left(\frac{\mu y_{E_{1}}^{*}+\alpha}{\beta}\right) & -\beta\left(\frac{\mu y_{E_{1}}^{*}+\alpha}{\beta}\right)-\left(\frac{\mu y_{E_{1}}^{*}+\alpha}{\beta}\right) & -\left(\frac{\mu y_{E_{1}}^{*}+\alpha}{\beta}\right) \\
\beta\left(\frac{\beta-\left(\alpha+(\beta+\mu) y_{E_{1}}^{*}\right)}{\beta(1+\beta)}\right) & 0 & -\mu\left(\frac{\beta-\left(\alpha+(\beta+\mu) y_{E_{1}}^{*}\right)}{\beta(1+\beta)}\right) \\
\eta_{1} y_{E_{1}}^{*} & \eta_{2} y_{E_{1}}^{*} & \frac{q}{y_{E_{1}}^{*}}
\end{array}\right]
$$

Nilai eigen dari $J\left(E_{1}\right)^{*}$ diperoleh dari $\operatorname{det}\left(J\left(E_{1}\right)^{*}-\lambda I\right)=0$, dimana $I$ adalah matriks identitas $3 \times 3$. Dari $\operatorname{det}\left(J\left(E_{1}\right)^{*}-\lambda I\right)=0$, diperoleh persamaan karakteristik (6)

$$
\lambda^{3}+\left(p_{1}-p_{2}\right) \lambda^{2}+\left(p_{3}-p_{4}\right) \lambda+\left(p_{5}-p_{6}\right)=0
$$

dengan,

$$
\begin{aligned}
p_{1}= & \frac{\mu y_{E_{1}}^{*}+\alpha}{\beta} \\
p_{2}= & \frac{q}{y_{E_{1}}^{*}} \\
p_{3}= & \frac{\left(\mu y_{E_{1}}^{*}+\alpha\right)\left(\beta-\left(\alpha+(\beta+\mu) y_{E_{1}}^{*}\right)\right)}{\beta+1}+\frac{\left(\mu y_{E_{1}}^{*}+\alpha\right) \eta_{1} y_{E_{1}}^{*}}{\beta} \\
& +\frac{\left(\mu y_{E_{1}}^{*}+\alpha\right)\left(\beta-\left(\alpha+(\beta+\mu) y_{E_{1}}^{*}\right)\right)}{\beta(1+\beta)}+\frac{\eta_{2} \mu y_{E_{1}}^{*}\left(\beta-\left(\alpha+(\beta+\mu) y_{E_{1}}^{*}\right)\right)}{\beta(1+\beta)} \\
p_{4}= & \left.\frac{\mu q}{\beta}+\frac{\alpha q}{\beta y_{E_{1}}^{*}}+\alpha\right)\left(\beta-\left(\alpha+(\beta+\mu) y_{E_{1}}^{*}\right)\right) \\
p_{5}= & \frac{\eta_{2} y_{E_{1}}^{*}\left(\mu y_{E_{1}}^{*}+\frac{\eta_{2} \mu y_{E_{1}}^{*}\left(\beta-\left(\alpha+(\beta+\mu) y_{E_{1}}^{*}\right)\right)}{\beta(\beta+1)}\right.}{(\beta+1) y_{E_{1}}^{*}} \\
p_{6}= & \frac{q\left(\mu y_{E_{1}}^{*}+\alpha\right)(\beta-(\alpha+1)}{\beta(\beta+1)}+\left(\frac{\mu\left(\mu y_{E_{1}}^{*}+\alpha\right)\left(\beta-\left(\alpha+(\beta+\mu) y_{E_{1}}^{*}\right)\right)}{\beta(\beta+1)}\right.
\end{aligned}
$$




$$
\left.+\frac{\mu\left(\mu y_{E_{1}}^{*}+\alpha\right)\left(\beta-\left(\alpha+(\beta+\mu) y_{E_{1}}^{*}\right)\right)}{\beta^{2}(\beta+1)}\right) \eta_{1} y_{E_{1}}^{*}+\frac{q\left(\mu y_{E_{1}}^{*}+\alpha\right)\left(\beta-\left(\alpha+(\beta+\mu) y_{E_{1}}^{*}\right)\right)}{\beta y_{E_{1}}^{*}(\beta+1)}
$$

Kestabilan titik kesetimbangan $E_{1}$ dijelaskan dalam Teorema 4.4

Teorema 4.4 Titik kesetimbangan $E_{1}$ stabil atau stabil asimptotik lokal, jika $k_{0}>0, p_{1}>$ $p_{2}, p_{3}>p_{4}, p_{5}>p_{6}$, dan $s_{1}>s_{2}$, dimana

$$
\begin{aligned}
& s_{1}=p_{1} p_{3}+p_{2} p_{4}+p_{6} \\
& s_{2}=p_{5}+p_{1} p_{4}+p_{2} p_{3}
\end{aligned}
$$

Sebaliknya, jika syarat stabil tidak terpenuhi maka titik kesetimbangan $E_{1}$ tidak stabil untuk semua syarat stabil tidak terpenuhi, atau tidak stabil saddle untuk salah satu syarat stabil tidak terpenuhi.

\subsection{Simulasi Numerik}

Simulasi numerik model (2) dilakukan dengan menggunakan metode Runge-Kutta orde 4 dengan bantuan software Phyton 3.7. Simulasi dilakukan dengan menggunakan nilai parameter pada Tabel 1.

Tabel 1: Nilai-nilai parameter

\begin{tabular}{|c|c|c|c|c|}
\hline \multirow{2}{*}{ Parameter } & \multicolumn{4}{|c|}{ Nilai } \\
\cline { 2 - 5 } & \multicolumn{2}{|c|}{$E_{0}$} & \multicolumn{2}{|c|}{$E_{1}$} \\
\cline { 2 - 5 } & $q=\frac{(o)^{2}}{4 \eta_{1}}$ & $q<\frac{(o)^{2}}{4 \eta_{1}}$ & $D y_{E_{1}}^{*}=0$ & $D y_{E_{1}}^{*}>0$ \\
\hline$\alpha$ & 0.1 & 0.1 & 0.388 & 0.02 \\
\hline$\beta$ & 0.02 & 0.02 & 0.5 & 0.05 \\
\hline$\delta$ & 0.2 & 0.2 & 0.02 & 0.003 \\
\hline$\eta_{1}$ & 0.4 & 0.4 & 0.000011 & 0.008 \\
\hline$\eta_{2}$ & 0.1 & 0.1 & 0.3701 & 0.030 \\
\hline$\mu$ & 0.2 & 0.2 & 0.387995428 & 0.032 \\
\hline$q$ & 0.025 & 0.001 & 0.00071 & 0.001 \\
\hline
\end{tabular}

\subsubsection{Simulasi Numerik Titik Kesetimbangan $E_{0}$}

Simulasi numerik titik kesetimbangan $E_{0}$ disimulasikan dengan menggunakan metode Runge-Kutta orde 4 dengan memberikan nilai-nilai pada parameter dan nilai awal. Nilai-nilai yang diberikan pada parameter harus memenuhi Teorema 4.1 agar titik kesetimbangan $E_{0} \in \mathbb{R}_{+}^{3}$ dan perlu diingat, bahwa setiap nilai awal yang diberikan bukanlah menggambarkan jumlah populasi melainkan proporsional dari setiap populasi. Simulasi numerik titik kesetimbangan $E_{0}$ diperlihatkan pada gambar (a) dan (b).
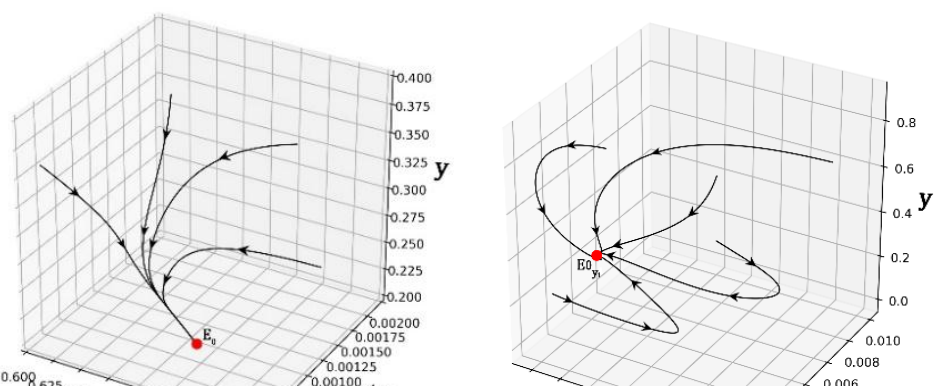


\begin{tabular}{|c|c|}
\hline Simulasi & Simulasi \\
\hline $\begin{array}{l}\text { Kesetimbangan } E_{0} \text { untuk } \\
q=\frac{(o)^{2}}{4 \eta}\end{array}$ & $\begin{array}{l}\text { Kesetimbangan } E_{0} \text { untuk } \\
q<\frac{(o)^{2}}{(\eta}\end{array}$ \\
\hline
\end{tabular}

Pada gambar (a) diperlihatkan bahwa titik kesetimbangan $E_{0}$ hanya memiliki satu titik kesetimbangan dan titik kesetimbangan $E_{0}$ stabil atau stabil asimptotik lokal. Sedangkan, pada gambar (b) diperlihatkan bahwa titik kesetimbangan $E_{0}$ memiliki dua titik kesetimbangan yang mana titik kesetimbangan $E_{0_{y_{2}}}$ tidak stabil saddle dan titik kesetimbangan $E_{0_{y_{1}}}$ stabil atau stabil asimptotik lokal.

\subsubsection{Simulasi Numerik Titik Kestimbangan $E_{1}$}

Simulasi numerik titik kesetimbangan $E_{1}$ disimulasikan dengan menggunakan metode Runge-Kutta orde 4 dengan memberikan nilai-nilai pada parameter dan nilai awal. Nilai-nilai yang diberikan pada parameter harus memenuhi Teorema 4.2. agar titik kesetimbangan $E_{1} \in \mathbb{R}_{+}^{3}$, dan perlu diingat, bahwa setiap nilai awal yang diberikan bukanlah menggambarkan jumlah populasi melainkan proporsional dari setiap populasi. Simulasi numerik titik kesetimbangan $E_{1}$ diperlihatkan pada gambar (c) dan (d).

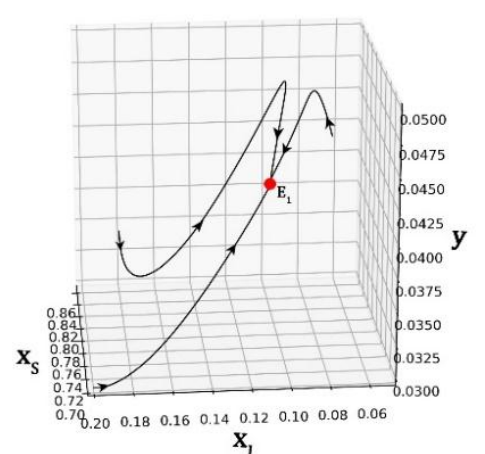

(a) Simulasi Titik Kesetimbangan $E_{1}$ untuk $D y_{E_{1}}^{*}=0$

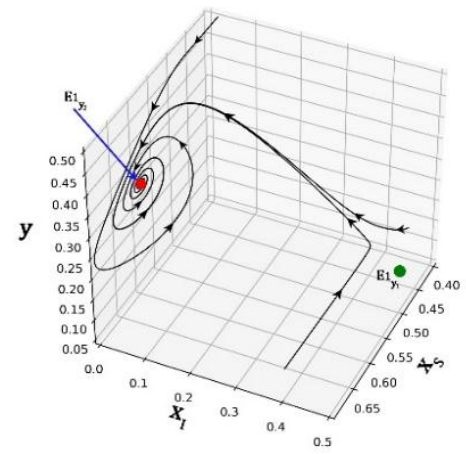

(b) Simulasi Titik Kesetimbangan $E_{1}$ untuk $D y_{E_{1}}^{*}>0$

Pada gambar (c) diperlihatkan bahwa titik kesetimbangan $E_{1}$ hanya memiliki satu titik kesetimbangan dan titik kesetimbangan $E_{1}$ stabil atau stabil asimptotik lokal. Sedangkan, pada gambar (d) diperlihatkan bahwa titik kesetimbangan $E_{1}$ memiliki dua titik kesetimbangan yang mana titik kesetimbangan $E_{1 y_{1}}$ tidak stabil saddle dan titik kesetimbangan $E_{1_{y_{2}}}$ stabil atau stabil asimptotik lokal.

\section{Kesimpulan}




\section{Nurhalis Hasan, Resmawan, Emli Rahmi}

Kestabilan dari titik kesetimbangan $E_{0}$ dan $E_{1}$ diuraikan pada Teorema 4.3 dan Teorema 4.4. Parameter Harvesting $\left(Q_{y}\right)$ pada predator berpengaruh terhadap eksistensi dari titik kesetimbangan $E_{0}$. Untuk pemanenan predator $\left(Q_{y}\right)$ sebesar $\frac{q r^{2}}{m_{1}}$ dimana $q=\frac{(o)^{2}}{4 \eta_{1}}$ diperoleh ada satu titik kesetimbangan $E_{0} \in \mathbb{R}_{+}^{3}$. Sedangkan, untuk pemanenan predator $\left(Q_{y}\right)$ sebesar $\frac{q r^{2}}{m_{1}}$ dimana $q<\frac{(o)^{2}}{4 \eta_{1}}$, diperoleh dua titik kesetimbangan $E_{0} \in \mathbb{R}_{+}^{3}$. Dari kestabilan titik $E_{0}$ dipereloh bahwa, jika populasi prey terinfeksi punah, keadaan populasi prey rentan dan populasi predator tidak akan punah, karena kedua populasi tersebut akan saling bergantung satu sama lain agar tidak ada populasi yang punah dan tidak ada populasi yang jumlahnya akan tumbuh berlebihan. Selain itu, dari kestabilan titik $E_{1}$ dipereloh bahwa populasi prey rentan, prey terinfeksi, dan predator saling bergantung satu sama lain, sehingga menyababkan tidak ada populasi yang punah.

\section{Daftar Pustaka}

[1] Berryman A. A., 1992. The Orgins and Evolution of Predator-Prey Theory, ESA Ecology Society of Amerika.

[2] Holling C. S., 1959. Some Characteristics of Simple Types of Predation and Parasitism. The Canadian Entomologist, The Canadian Entomologist, Vol. XCI, No.7.

[3] Anderson R. M., \& May R. M., 1986. The Invasion, Persistence and Spread of Infectious Diseases within Animal and Plant Communities: Discussion, Philosophical Transactions of The Royal Society B Biological Sciences, Vol.314, No.1.

[4] Chattopadhyay J., \& Bairagi N., 2001. Pelicans at Risk in Salton Sea, Ecological Modelling-ECOL MODEL, Vol. 136.

[5] Purnomo, A. S. Darti I., \& Suryanto A., 2017. "Dynamics od Eco-Epidemiological Model with Harvesting". AIP Conference Proceedings.

[6] Jha P.K., dan Ghorai S., 2017. "Stability of Prey-Predator Model with Holling Type Response Function and Selective Harvesting", Journal of Applied \& Computational Mathematics, Vol. 06.

[7] Edelstein-Keshet L., 2005. "Mathematical Models in Biology", SIAM, Canada.

[8] Perko L., 2001. "Differential Equations and Dynamical System ", Springer, New York.

\section{Lampiran}

Teorema 4.1 Titik kesetimbangan $E_{0} \in R_{+}^{3}$ jika

a) $q<\frac{(o)^{2}}{4 \eta_{1}}, \eta_{1}>\delta$ dan $0<y_{E_{0}}^{*}<1$. Kondisi ini menghasilkan dua titik kesetimbangan $E_{0} \in R_{+}^{3}$, atau

b) $q=\frac{(o)^{2}}{4 \eta_{1}}, \eta_{1}>\delta$ dan $0<y_{E_{0}}^{*}<1$. Kondisi ini menghasilkan satu titik kesetimbangan $E_{0} \in R_{+}^{3}$. 


\section{Bukti}

Eksistensi titik kesetimbangan $E_{0}$ bergantung pada nilai $y_{E_{0}}^{*}$. Nilai $y_{E_{0}}^{*}$ diperoleh dari persamaan kuadrat yang disajikan pada persamaan (7)

$$
\eta_{1} y^{2}+(o) y+q=0
$$

dengan $o=\delta-\eta_{1} \cdot y_{E_{0}}^{*}$ dapat dituliskan kembali dengan

dengan $o=\delta-\eta_{1}$.

$$
\begin{aligned}
y_{1,2} & =\frac{-(o) \pm \sqrt{D y_{E_{0}}^{*}}}{2 \eta_{1}} \\
D y_{E_{0}}^{*}= & (o)^{2}-4 \eta_{1} q .
\end{aligned}
$$

a) Kasus a

Akan ditunjukan $q<\frac{(o)^{2}}{4 \eta_{1}}, \eta_{1}>\delta$ dan $0<y_{E_{0}}^{*}<1$ sehingga menghasilkan dua titik kesetimbangan $E_{0} \in \mathbb{R}_{+}^{3}$. Untuk $q<\frac{(o)^{2}}{4 \eta_{1}}$

$$
\begin{aligned}
q & <\frac{(o)^{2}}{4 \eta_{1}} \\
4 \eta_{1} q & <(o)^{2} \\
(o)^{2}-4 \eta_{1} q & >0 \\
\Rightarrow D y_{E_{0}}^{*} & >0
\end{aligned}
$$

Karena $D y_{E_{0}}^{*}>0$, kondisi ini menyebabkan $y_{1}=y_{E_{0}}^{*} \neq y_{2}=y_{E_{0}}^{*}$. Untuk $\eta_{1}>\delta$

$$
\begin{aligned}
\eta_{1} & >\delta \\
\delta-\eta_{1} & <0 \\
-\left(\delta-\eta_{1}\right) & >0 \\
\Rightarrow-(O) & >0
\end{aligned}
$$

Karena $q<\frac{(o)^{2}}{4 \eta_{1}}$ dan $\eta_{1}>\delta$, kondisi ini membuktikan $y_{E_{0}}^{*}>0$. Untuk

$$
0<y_{E_{0}}^{*}<1
$$

$$
\begin{array}{r}
y_{E_{0}}^{*}<1 \\
1-y_{E_{0}}^{*}>0 \\
\Rightarrow x_{s}>0
\end{array}
$$

Karena $y_{E_{0}}^{*}>0$ dan $y_{E_{0}}^{*}<1$, kondisi ini membuktikan populasi $x_{S}>0$. Dengan demikian terbukti bahwa persamaan (7) membuat ada dua titik kesetimbangan $E_{0} \in \mathbb{R}_{+}^{3}$, jika $q>\frac{(o)^{2}}{4 \eta_{1}}, \eta_{1}<\delta$, dan $0<y_{E_{0}}^{*}<1$.

b) Kasus b

Akan ditunjukan $q=\frac{(o)^{2}}{4 \eta_{1}}, \quad \eta_{1}>\delta$ dan $0<y_{E_{0}}^{*}<1$, sehingga mengahasilkan satu titik kesetimbangan $E_{0} \in \mathbb{R}_{+}^{3}$. Untuk $q=\frac{(o)^{2}}{4 \eta_{1}}$ 


$$
\begin{gathered}
q=\frac{(o)^{2}}{4 \eta_{1}} \\
4 \eta_{1} q=(o)^{2} \\
(o)^{2}-4 \eta_{1} q=0 \\
\Rightarrow D y_{E_{0}}^{*}=0
\end{gathered}
$$

Karena $D y_{E_{0}}^{*}=0$, kondisi ini menyebabkan $y_{1}=y_{2}=y_{E_{0}}^{*}$. Untuk $\eta_{1}>\delta$

$$
\begin{gathered}
\eta_{1}>\delta \\
\delta-\eta_{1}<0 \\
-\left(\delta-\eta_{1}\right)>0 \\
\Rightarrow-(0)>0
\end{gathered}
$$

Karena $q=\frac{(o)^{2}}{4 \eta_{1}}$ dan $\eta_{1}>\delta$, kondisi ini membuktikan $y_{E_{0}}^{*}>0$. Untuk

$$
\begin{aligned}
& \\
& y_{E_{0}}^{*}<1 \\
1-y_{E_{0}}^{*}<1 & y_{E_{0}}^{*}>0 \\
\Rightarrow & x_{s}>0
\end{aligned}
$$

Karena $y_{E_{0}}^{*}>0$ dan $y_{E_{0}}^{*}<1$, kondisi ini membuktikan $x_{S}>0$. Sehingga, terbukti persamaan (7) membuat ada satu titik kesetimbangan $E_{0} \in \mathbb{R}_{+}^{3}$, jika $q=\frac{(o)^{2}}{4 \eta_{1}}, \eta_{1}<\delta$, dan $y_{E_{0}}^{*}<1$.

\section{Teorema 4.2}

a) $E_{1}$ tidak terdapat di $R_{+}^{3}$ jika $D y_{E_{1}}^{*}<0$. Kondisi ini tidak menghasilkan titik interior.

b) $E_{1} \in R_{+}^{3} j i k a D y_{E_{1}}^{*}>0$ dan :

i). $\max \left\{\frac{d_{4}-\eta_{2} \beta}{\alpha(1+\beta)}, \frac{d_{2}}{\mu(1+\beta)}\right\}<\eta_{1}<\frac{d_{4}+\sqrt{D y_{E_{1}}^{*}}-\eta_{2} \beta}{\alpha(1+\beta)}$, dan $\alpha<\beta-(\beta+\mu) y_{E_{1}}^{*}$, atau

ii). $\max \left\{\frac{d_{4}-\eta_{2} \beta}{a(1+\beta)}, \frac{d_{4}-\sqrt{D y_{E_{1}}^{*}}-\eta 2 \beta}{\alpha(1+\beta)}\right\}<\eta_{1}<\frac{d_{2}}{\mu(1+\beta)}$, dan $\alpha<\beta-(\beta+\mu) y_{E_{1}}^{*}$, atau

iii). $\max \left\{\frac{d_{4}-\sqrt{D y_{E_{1}}^{*}}-\eta_{2} \beta}{\alpha(1+\beta)}, \frac{d_{2}}{\mu(1+\beta)}\right\}<\eta_{1}<\frac{d_{4}-\eta_{2} \beta}{a(1+\beta)}$, dan $\alpha<\beta-(\beta+\mu) y_{E_{1}}^{*}$, atau

iv). $\eta_{1}<\min \left\{\frac{d_{4}-\eta_{2} \beta}{a(1+\beta)}, \frac{d_{4}+\sqrt{D y_{E_{1}}^{*}}-\eta_{2} \beta}{\alpha(1+\beta)}, \frac{d_{2}}{\mu(1+\beta)}\right\}$, dan $\alpha<\beta-(\beta+\mu) y_{E_{1}}^{*}$, atau

v). $\max \left\{\frac{d_{4}+\sqrt{D y_{E_{1}}^{*}}-\eta_{2} \beta}{\alpha(1+\beta)}, \frac{d_{2}}{\mu(1+\beta)}\right\}<\eta_{1}<\frac{d_{4}-\eta_{2} \beta}{a(1+\beta)}$, dan $\alpha<\beta-(\beta+\mu) y_{E_{1}}^{*}$.

Kondisi ini menghasilkan dua titik kesetimbangan $E_{1} \in R_{+}^{3}$.

c) $E_{1} \in R_{+}^{3} j i k a D y_{E_{1}}^{*}=0$ dan

i). $\frac{d_{4}-\eta_{2} \beta}{a(1+\beta)}<\eta_{1}<\frac{d_{2}}{\mu(1+\beta)}$, dan $\alpha<\beta-(\beta+\mu) y_{E_{1}}^{*}$, atau 
ii). $\frac{d_{2}}{\mu(1+\beta)}<\eta_{1}<\frac{d_{4}-\eta_{2} \beta}{a(1+\beta)}$, dan $\alpha<\beta-(\beta+\mu) y_{E_{1}}^{*}$.

Kondisi ini menghasilkan satu titik kesetimbangan $E_{1} \in R_{+}^{3}$.

\section{Bukti}

Eksistensi $E_{1}$ bergantung pada nilai $y_{E_{1}}^{*}$, dan selama diskriminan $\left(D y_{E_{1}}^{*}\right)$ dari $y_{E_{1}}^{*}$ tak negatif. Nilai $y_{E_{1}}^{*}$ diperoleh dari persamaan kuadrat yang disajikan pada persamaan (8)

$$
\left(d_{1}-d_{2}\right) y^{2}+\left(d_{3}-d_{4}\right) y-q \beta(1+\beta)=0
$$

dimana

$$
\begin{aligned}
& d_{1}=\eta_{1} \mu(1+\beta) \\
& d_{2}=\eta_{2}(\mu+\beta) \\
& d_{3}=\eta_{1} \alpha(1+\beta)+\eta_{2} \beta \\
& d_{4}=\eta_{2} \alpha+\delta \beta(1+\beta)
\end{aligned}
$$

a) Kasus a

Akan ditunjukan $E_{1}$ tidak terdapat di $\mathbb{R}_{+}^{3}$, jika $D y_{E_{1}}^{*}<0$.

$$
\begin{aligned}
y_{1,2} & =\frac{-\left(d_{3}-d_{4}\right) \pm \sqrt{D y_{E_{1}}^{*}}}{2\left(d_{1}-d_{2}\right)} \\
D y_{E_{1}}^{*} & =\left(d_{3}-d_{4}\right)^{2}-4\left(d_{1}-d_{2}\right) q \beta(1+\beta)
\end{aligned}
$$

$y_{1,2}$ merupakan akar-akar real dari persamaan (8) dan $D y_{E_{1}}^{*}$ merupakan diskriminan dari persamaan (8), jika $D y_{E_{1}}^{*}<0$, maka $\sqrt{D y_{E_{1}}^{*}}$ akan bernilai kompleks dan membuat $y_{E_{1}}^{*}$ bernilai kompleks, sehingga terbukti $E_{1}$ tidak terdapat di $R_{+}^{3}$.

b) Kasus b

Karena $D y_{E_{1}}^{*}>0$, maka $y_{1}=y_{E_{1}}^{*} \neq y_{2}=y_{E_{1}}^{*}$. Sehingga, dapat dituliskan kembali $y_{E_{1}}^{*}$ sebagai berikut

$$
\begin{aligned}
y_{1} & =\frac{-\left(d_{3}-d_{4}\right)+\sqrt{D y_{E_{1}}^{*}}}{2\left(d_{1}-d_{2}\right)} \\
y_{2} & =\frac{-\left(d_{3}-d_{4}\right)-\sqrt{D y_{E_{1}}^{*}}}{2\left(d_{1}-d_{2}\right)} \\
D y_{E_{1}}^{*} & =\left(d_{3}-d_{4}\right)^{2}-4\left(d_{1}-d_{2}\right) q \beta(1+\beta)
\end{aligned}
$$

Akar-akar real dari persamaan (8) untuk kondisi ini akan bernilai positif jika memenuhi salah satu dari lima kasus berikut:

i). Kasus 1

$$
\begin{aligned}
\eta_{1} & >\frac{d_{4}-\eta_{2} \beta}{\alpha(1+\beta)} \\
\eta_{1} \alpha(1+\beta) & >d_{4}-\eta_{2} \beta \\
\eta_{1} \alpha(1+\beta)+\eta_{2} \beta-d_{4} & >0 \\
\Rightarrow d_{3}-d_{4} & >0
\end{aligned}
$$


dan

$$
\begin{gathered}
\eta_{1}<\frac{d_{4}+\sqrt{D y_{E_{1}}^{*}}-\eta_{2} \beta}{\alpha(1+\beta)} \\
\eta_{1} \alpha(1+\beta)<d_{4}+\sqrt{D y_{E_{1}}^{*}}-\eta_{2} \beta \\
\eta_{1} \alpha(1+\beta)+\eta_{2} \beta<d_{4}+\sqrt{D y_{E_{1}}^{*}} \\
d_{3}-d_{4}-\sqrt{D y_{E_{1}}^{*}}<0 \\
\Rightarrow-\left(d_{3}-d_{4}\right)+\sqrt{D y_{E_{1}}^{*}}>0
\end{gathered}
$$

dan

$$
\begin{aligned}
\eta_{1} & >\frac{d_{2}}{\mu(1+\beta)} \\
\eta_{1} \mu(1+\beta) & >d_{2} \\
d_{1} & >d_{2} \\
d_{1}-d_{2} & >0 \\
\Rightarrow 2\left(d_{1}-d_{2}\right) & >0
\end{aligned}
$$

sehingga irisan dari $\eta_{1}>\frac{d_{4}-\eta_{2} \beta}{\alpha(1+\beta)}, \eta_{1}<\frac{d_{4}+\sqrt{D y_{E_{1}}^{*}}-\eta_{2} \beta}{\alpha(1+\beta)}$, dan $\eta_{1}>\frac{d_{2}}{\mu(1+\beta)}$ adalah

$$
\max \left\{\frac{d_{4}-\eta_{2} \beta}{\alpha(1+\beta)}, \frac{d_{2}}{\mu(1+\beta)}\right\}<\eta_{1}<\frac{d_{4}+\sqrt{D y_{E_{1}}^{*}}-\eta_{2} \beta}{\alpha(1+\beta)}
$$

Kondisi ini membuktikan $y_{E_{1}}^{*}=y_{1}>0$, jika

dan

$$
\max \left\{\frac{d_{4}-\eta_{2} \beta}{\alpha(1+\beta)}, \frac{d_{2}}{\mu(1+\beta)}\right\}<\eta_{1}<\frac{d_{4}+\sqrt{D y_{E_{1}}^{*}}-\eta_{2} \beta}{\alpha(1+\beta)}
$$

$$
\begin{aligned}
& \alpha<\beta-(\beta+\mu) y_{E_{1}}^{*} \\
& \beta-(\beta+\mu) y_{E_{1}}^{*}-\alpha>0 \\
& \beta-\left(\alpha+(\beta+\mu) y_{E_{1}}^{*}\right)>0 \\
& \frac{\beta-\left(\alpha+(\beta+\mu) y_{E_{1}}^{*}\right)}{2(1+\beta)}>0 \\
& \Rightarrow x_{I}>0
\end{aligned}
$$

Karena $y_{E_{1}}^{*}=y_{1}>0$ dan $x_{I}>0$, terbukti titik kesetimbangan $E_{1} \in \mathbb{R}_{+}^{3}$, jika $\max \left\{\frac{d_{4}-\eta_{2} \beta}{\alpha(1+\beta)}, \frac{d_{2}}{\mu(1+\beta)}\right\}<\eta_{1}<\frac{d_{4}+\sqrt{D y_{E_{1}}^{*}}-\eta_{2} \beta}{\alpha(1+\beta)}$ dan $\alpha<\beta-(\beta+\mu) y_{E_{1}}^{*}$.

ii). Kasus 2 


$$
\begin{aligned}
\eta_{1} & >\frac{d_{4}-\eta_{2} \beta}{\alpha(1+\beta)} \\
\eta_{1} \alpha(1+\beta) & >d_{4}-\eta_{2} \beta \\
\eta_{1} \alpha(1+\beta)+\eta_{2} \beta-d_{4} & >0 \\
\Rightarrow d_{3}-d_{4} & >0
\end{aligned}
$$

dan

$$
\begin{gathered}
\eta_{1}>\frac{d_{4}-\sqrt{D y_{E_{1}}^{*}}-\eta_{2} \beta}{\alpha(1+\beta)} \\
\eta_{1} \alpha(1+\beta)>d_{4}-\sqrt{D y_{E_{1}}^{*}}-\eta_{2} \beta \\
\eta_{1} \alpha(1+\beta)+\eta_{2} \beta>d_{4}-\sqrt{D y_{E_{1}}^{*}} \\
d_{3}-d_{4}+\sqrt{D y_{E_{1}}^{*}}>0 \\
\Rightarrow-\left(d_{3}-d_{4}\right)-\sqrt{D y_{E_{1}}^{*}}<0
\end{gathered}
$$

dan

$$
\begin{aligned}
\eta_{1} & <\frac{d_{2}}{\mu(1+\beta)} \\
\eta_{1} \mu(1+\beta) & <d_{2} \\
d_{1} & <d_{2} \\
d_{1}-d_{2} & <0 \\
\Rightarrow 2\left(d_{1}-d_{2}\right) & <0
\end{aligned}
$$

sehingga irisan dari $\eta_{1}>\frac{d_{4}-\eta_{2} \beta}{\alpha(1+\beta)}, \eta_{1}>\frac{d_{4}-\sqrt{D y_{E_{1}}^{*}}-\eta_{2} \beta}{\alpha(1+\beta)}$, dan $\eta_{1}<\frac{d_{2}}{\mu(1+\beta)}$ adalah

$$
\max \left\{\frac{d_{4}-\eta_{2} \beta}{\alpha(1+\beta)}, \frac{d_{4}-\sqrt{D y_{E_{1}}^{*}}-\eta_{2} \beta}{\alpha(1+\beta)}\right\}<\eta_{1}<\frac{d_{2}}{\mu(1+\beta)}
$$

Kondisi ini membuktikan $y_{E_{1}}^{*}=y_{2}>0$, jika

$$
\max \left\{\frac{d_{4}-\eta_{2} \beta}{\alpha(1+\beta)}, \frac{d_{4}-\sqrt{D y_{E_{1}}^{*}}-\eta_{2} \beta}{\alpha(1+\beta)}\right\}<\eta_{1}<\frac{d_{2}}{\mu(1+\beta)}
$$

dan

$$
\begin{aligned}
& \alpha<\beta-(\beta+\mu) y_{E_{1}}^{*} \\
& \beta-(\beta+\mu) y_{E_{1}}^{*}-\alpha>0 \\
& \beta-\left(\alpha+(\beta+\mu) y_{E_{1}}^{*}\right)>0 \\
& \frac{\beta-\left(\alpha+(\beta+\mu) y_{E_{1}}^{*}\right)}{2(1+\beta)}>0 \\
& \Rightarrow x_{I}>0
\end{aligned}
$$


Karena $y_{E_{1}}^{*}=y_{2}>0$ dan $x_{I}>0$, terbukti titik kesetimbangan $E_{1} \in \mathbb{R}_{+}^{3}$, jika $\max \left\{\frac{d_{4}-\eta_{2} \beta}{\alpha(1+\beta)}, \frac{d_{4}-\sqrt{D y_{E_{1}}^{*}}-\eta_{2} \beta}{\alpha(1+\beta)}\right\}<\eta_{1}<\frac{d_{2}}{\mu(1+\beta)}$, dan $\alpha<\beta-(\beta+\mu) y_{E_{1}}^{*} \cdot \square$

iii). Kasus 3

$$
\begin{aligned}
\eta_{1} & <\frac{d_{4}-\eta_{2} \beta}{\alpha(1+\beta)} \\
\eta_{1} \alpha(1+\beta) & <d_{4}-\eta_{2} \beta \\
\eta_{1} \alpha(1+\beta)+\eta_{2} \beta-d_{4} & <0 \\
\Rightarrow d_{3}-d_{4} & <0
\end{aligned}
$$

dan

$$
\begin{aligned}
\eta_{1} & >\frac{d_{4}-\sqrt{D y_{E_{1}}^{*}}-\eta_{2} \beta}{\alpha(1+\beta)} \\
\eta_{1} \alpha(1+\beta) & >d_{4}-\sqrt{D y_{E_{1}}^{*}}-\eta_{2} \beta \\
\eta_{1} \alpha(1+\beta)+\eta_{2} \beta & >d_{4}-\sqrt{D y_{E_{1}}^{*}} \\
d_{3} & >d_{4}-\sqrt{D y_{E_{1}}^{*}} \\
\Rightarrow d_{3}-d_{4}+\sqrt{D y_{E_{1}}^{*}} & >0
\end{aligned}
$$

dan

$$
\begin{aligned}
\eta_{1} & >\frac{d_{2}}{\mu(1+\beta)} \\
\eta_{1} \mu(1+\beta) & >d_{2} \\
d_{1} & >d_{2} \\
d_{1}-d_{2} & >0 \\
\Rightarrow 2\left(d_{1}-d_{2}\right) & >0
\end{aligned}
$$

sehingga irisan dari $\eta_{1}<\frac{d_{4}-\eta_{2} \beta}{\alpha(1+\beta)}, \eta_{1}>\frac{d_{4}-\sqrt{D y_{E_{1}}^{*}}-\eta_{2} \beta}{\alpha(1+\beta)}$, dan $\eta_{1}>\frac{d_{2}}{\mu(1+\beta)}$ adalah

$$
\max \left\{\frac{d_{4}-\sqrt{D y_{E_{1}}^{*}}-\eta_{2} \beta}{\alpha(1+\beta)}, \frac{d_{2}}{\mu(1+\beta)}\right\}<\eta_{1}<\frac{d_{4}-\eta_{2} \beta}{\alpha(1+\beta)}
$$

Kondisi ini membuktikan $y_{E_{1}}^{*}=y_{1}>0$, jika

$$
\max \left\{\frac{d_{4}-\sqrt{D y_{E_{1}}^{*}}-\eta_{2} \beta}{\alpha(1+\beta)}, \frac{d_{2}}{\mu(1+\beta)}\right\}<\eta_{1}<\frac{d_{4}-\eta_{2} \beta}{\alpha(1+\beta)}
$$

dan

$$
\alpha<\beta-(\beta+\mu) y_{E_{1}}^{*}
$$




$$
\begin{aligned}
\beta-(\beta+\mu) y_{E_{1}}^{*}-\alpha & >0 \\
\beta-\left(\alpha+(\beta+\mu) y_{E_{1}}^{*}\right) & >0 \\
\frac{\beta-\left(\alpha+(\beta+\mu) y_{E_{1}}^{*}\right)}{2(1+\beta)} & >0 \\
\Rightarrow x_{I} & >0
\end{aligned}
$$

Karena $y_{E_{1}}^{*}=y_{1}>0$ dan $x_{I}>0$, terbukti titik kesetimbangan $E_{1} \in \mathbb{R}_{+}^{3}$, jika $\max \left\{\frac{d_{4}-\sqrt{D y_{E_{1}}^{*}}-\eta_{2} \beta}{\alpha(1+\beta)}, \frac{d_{2}}{\mu(1+\beta)}\right\}<\eta_{1}<\frac{d_{4}-\eta_{2} \beta}{\alpha(1+\beta)}$ dan $\alpha<\beta-(\beta+\mu) y_{E_{1}}^{*}$.

iv). Kasus 4

$$
\begin{aligned}
\eta_{1} & <\frac{d_{4}-\eta_{2} \beta}{\alpha(1+\beta)} \\
\eta_{1} \alpha(1+\beta) & <d_{4}-\eta_{2} \beta \\
\eta_{1} \alpha(1+\beta)+\eta_{2} \beta-d_{4} & <0 \\
\Rightarrow d_{3}-d_{4} & <0
\end{aligned}
$$

dan

$$
\begin{aligned}
\eta_{1} & <\frac{d_{4}+\sqrt{D y_{E_{1}}^{*}}-\eta_{2} \beta}{\alpha(1+\beta)} \\
\eta_{1} \alpha(1+\beta) & <d_{4}+\sqrt{D y_{E_{1}}^{*}}-\eta_{2} \beta \\
\eta_{1} \alpha(1+\beta)+\eta_{2} \beta & <d_{4}+\sqrt{D y_{E_{1}}^{*}} \\
d_{3} & <d_{4}+\sqrt{D y_{E_{1}}^{*}} \\
\Rightarrow d_{3}-d_{4}-\sqrt{D y_{E_{1}}^{*}} & <0
\end{aligned}
$$

dan

$$
\begin{aligned}
\eta_{1} & <\frac{d_{2}}{\mu(1+\beta)} \\
\eta_{1} \mu(1+\beta) & <d_{2} \\
d_{1} & <d_{2} \\
d_{1}-d_{2} & <0 \\
\Rightarrow 2\left(d_{1}-d_{2}\right) & <0
\end{aligned}
$$

sehingga irisan dari $\eta_{1}<\frac{d_{4}-\eta_{2} \beta}{\alpha(1+\beta)}, \eta_{1}<\frac{d_{4}+\sqrt{D y_{E_{1}}^{*}}-\eta_{2} \beta}{\alpha(1+\beta)}$, dan $\eta_{1}<\frac{d_{2}}{\mu(1+\beta)}$ adalah

$$
\eta_{1}<\min \left\{\frac{d_{4}-\eta_{2} \beta}{\alpha(1+\beta)}, \frac{d_{4}+\sqrt{D y_{E_{1}}^{*}}-\eta_{2} \beta}{\alpha(1+\beta)}, \frac{d_{2}}{\mu(1+\beta)}\right\} \text {. }
$$


Kondisi ini membuktikan $y_{E_{1}}^{*}=y_{2}>0$, jika

$$
\eta_{1}<\min \left\{\frac{d_{4}-\eta_{2} \beta}{\alpha(1+\beta)}, \frac{d_{4}+\sqrt{D y_{E_{1}}^{*}}-\eta_{2} \beta}{\alpha(1+\beta)}, \frac{d_{2}}{\mu(1+\beta)}\right\}
$$

dan

$$
\begin{aligned}
& \alpha<\beta-(\beta+\mu) y_{E_{1}}^{*} \\
& \beta-(\beta+\mu) y_{E_{1}}^{*}-\alpha>0 \\
& \beta-\left(\alpha+(\beta+\mu) y_{E_{1}}^{*}\right)>0 \\
& \frac{\beta-\left(\alpha+(\beta+\mu) y_{E_{1}}^{*}\right)}{2(1+\beta)}>0 \\
& \Rightarrow x_{I}>0
\end{aligned}
$$

Karena $y_{E_{1}}^{*}=y_{2}>0$ dan $x_{I}>0$, terbukti titik kesetimbangan $E_{1} \in \mathbb{R}_{+}^{3}$, jika $\eta_{1}<\min \left\{\frac{d_{4}-\eta_{2} \beta}{\alpha(1+\beta)}, \frac{d_{4}+\sqrt{D y_{E_{1}}^{*}}-\eta_{2} \beta}{\alpha(1+\beta)}, \frac{d_{2}}{\mu(1+\beta)}\right\}$, dan $\alpha<\beta-(\beta+\mu) y_{E_{1}}^{*}$.

v). Kasus 5

$$
\begin{aligned}
\eta_{1} & <\frac{d_{4}-\eta_{2} \beta}{\alpha(1+\beta)} \\
\eta_{1} \alpha(1+\beta) & <d_{4}-\eta_{2} \beta \\
\eta_{1} \alpha(1+\beta)+\eta_{2} \beta-d_{4} & <0 \\
\Rightarrow d_{3}-d_{4} & <0
\end{aligned}
$$

dan

$$
\begin{aligned}
\eta_{1} & >\frac{d_{4}+\sqrt{D y_{E_{1}}^{*}}-\eta_{2} \beta}{\alpha(1+\beta)} \\
\eta_{1} \alpha(1+\beta) & >d_{4}+\sqrt{D y_{E_{1}}^{*}}-\eta_{2} \beta \\
\eta_{1} \alpha(1+\beta)+\eta_{2} \beta & >d_{4}+\sqrt{D y_{E_{1}}^{*}} \\
d_{3} & >d_{4}+\sqrt{D y_{E_{1}}^{*}} \\
\Rightarrow d_{3}-d_{4}-\sqrt{D y_{E_{1}}^{*}} & >0
\end{aligned}
$$

dan

$$
\begin{aligned}
\eta_{1} & >\frac{d_{2}}{\mu(1+\beta)} \\
\eta_{1} \mu(1+\beta) & >d_{2} \\
d_{1} & >d_{2} \\
d_{1}-d_{2} & >0 \\
\Rightarrow 2\left(d_{1}-d_{2}\right) & >0
\end{aligned}
$$


sehingga irisan dari $\eta_{1}<\frac{d_{4}-\eta_{2} \beta}{\alpha(1+\beta)}, \eta_{1}>\frac{d_{4}+\sqrt{D y_{E_{1}}^{*}}-\eta_{2} \beta}{\alpha(1+\beta)}$, dan $\eta_{1}>\frac{d_{2}}{\mu(1+\beta)}$ adalah

$$
\max \left\{\frac{d_{4}+\sqrt{D y_{E_{1}}^{*}}-\eta_{2} \beta}{\alpha(1+\beta)}, \frac{d_{2}}{\mu(1+\beta)}\right\}<\eta_{1}<\frac{d_{4}-\eta_{2} \beta}{\alpha(1+\beta)}
$$

Kondisi ini membuktikan $y_{E_{1}}^{*}=y_{2}>0$, jika

dan

$$
\max \left\{\frac{d_{4}+\sqrt{D y_{E_{1}}^{*}}-\eta_{2} \beta}{\alpha(1+\beta)}, \frac{d_{2}}{\mu(1+\beta)}\right\}<\eta_{1}<\frac{d_{4}-\eta_{2} \beta}{\alpha(1+\beta)}
$$

$$
\begin{aligned}
& \alpha<\beta-(\beta+\mu) y_{E_{1}}^{*} \\
& \beta-(\beta+\mu) y_{E_{1}}^{*}-\alpha>0 \\
& \beta-\left(\alpha+(\beta+\mu) y_{E_{1}}^{*}\right)>0 \\
& \frac{\beta-\left(\alpha+(\beta+\mu) y_{E_{1}}^{*}\right)}{2(1+\beta)}>0 \\
& \Rightarrow x_{I}>0
\end{aligned}
$$

Karena $y_{E_{1}}^{*}=y_{1}>0$ dan $x_{I}>0$, terbukti titik kesetimbangan $E_{1} \in \mathbb{R}_{+}^{3}$, jika $\max \left\{\frac{d_{4}+\sqrt{D y_{E_{1}}^{*}}-\eta_{2} \beta}{\alpha(1+\beta)}, \frac{d_{2}}{\mu(1+\beta)}\right\}<\eta_{1}<\frac{d_{4}-\eta_{2} \beta}{\alpha(1+\beta)}$ dan $\alpha<\beta-(\beta+\mu) y_{E_{1}}^{*}$.

Dengan demikian, terbukti bahwa persamaan (8) membuat ada dua titik kesetimbangan $E_{1} \in \mathbb{R}_{+}^{3}$, jika $D y_{E_{1}}^{*}>0$ dan terpenuhi salah satu dari ke-lima kasus yang ada. $\square$

(a). Kasus c

Karena $\boldsymbol{D} y_{E_{1}}^{*}=0$, maka $y_{1}=y_{2}=y_{E_{1}}^{*}$. Sehingga, dapat dituliskan kembali $y_{E_{1}}^{*}$ sebagai berikut

$$
y_{1}=y_{2}=\frac{-\left(d_{3}-d_{4}\right)}{2\left(d_{1}-d_{2}\right)}
$$

Akar-akar real dari persamaan (8) untuk kondisi ini akan bernilai positif jika memenuhi salah satu dari dua kasus berikut:

i). Kasus 1

$$
\begin{aligned}
\eta_{1} & <\frac{d_{4}-\eta_{2} \beta}{\alpha(1+\beta)} \\
\eta_{1} \alpha(1+\beta) & <d_{4}-\eta_{2} \beta \\
\eta_{1} \alpha(1+\beta)+\eta_{2} \beta-d_{4} & <0 \\
\Rightarrow d_{3}-d_{4} & <0
\end{aligned}
$$

dan 


$$
\begin{aligned}
\eta_{1} & >\frac{d_{2}}{\mu(1+\beta)} \\
\eta_{1} \mu(1+\beta) & >d_{2} \\
d_{1} & >d_{2} \\
d_{1}-d_{2} & >0 \\
\Rightarrow 2\left(d_{1}-d_{2}\right) & >0
\end{aligned}
$$

sehingga irisan dari $\eta_{1}<\frac{d_{4}-\eta_{2} \beta}{\alpha(1+\beta)}$ dan $\eta_{1}>\frac{d_{2}}{\mu(1+\beta)}$ adalah

$$
\frac{d_{2}}{\mu(1+\beta)}<\eta_{1}<\frac{d_{4}-\eta_{2} \beta}{\alpha(1+\beta)}
$$

Kondisi ini membuktikan $y_{1}=y_{2}=y_{E_{1}}^{*}>0$, jika $\frac{d_{2}}{\mu(1+\beta)}<\eta_{1}<\frac{d_{4}-\eta_{2} \beta}{\alpha(1+\beta)}$, dan

$$
\alpha<\beta-(\beta+\mu) y_{E_{1}}^{*}
$$

$$
\begin{aligned}
& \beta-(\beta+\mu) y_{E_{1}}^{*}-\alpha>0 \\
& \beta-\left(\alpha+(\beta+\mu) y_{E_{1}}^{*}\right)>0 \\
& \frac{\beta-\left(\alpha+(\beta+\mu) y_{E_{1}}^{*}\right)}{2(1+\beta)}>0 \\
& \Rightarrow x_{I}>0
\end{aligned}
$$

Karena $y_{1}=y_{2}=y_{E_{1}}^{*}>0$ dan $x_{I}>0$. Terbukti titik kesetimbangan $E_{1} \in \mathbb{R}_{+}^{3}$, jika $\frac{d_{2}}{\mu(1+\beta)}<\eta_{1}<\frac{d_{4}-\eta_{2} \beta}{\alpha(1+\beta)}$ dan $\alpha<\beta-(\beta+\mu) y_{E_{1}}^{*}$.

ii). Kasus 2

$$
\begin{aligned}
\eta_{1} & >\frac{d_{4}-\eta_{2} \beta}{\alpha(1+\beta)} \\
\eta_{1} \alpha(1+\beta) & >d_{4}-\eta_{2} \beta \\
\eta_{1} \alpha(1+\beta)+\eta_{2} \beta-d_{4} & >0 \\
\Rightarrow d_{3}-d_{4} & >0
\end{aligned}
$$

dan

$$
\begin{aligned}
\eta_{1} & <\frac{d_{2}}{\mu(1+\beta)} \\
\eta_{1} \mu(1+\beta) & <d_{2} \\
d_{1} & <d_{2} \\
d_{1}-d_{2} & <0 \\
\Rightarrow 2\left(d_{1}-d_{2}\right) & <0
\end{aligned}
$$

sehingga irisan dari $\eta_{1}>\frac{d_{4}-\eta_{2} \beta}{\alpha(1+\beta)}$ dan $\eta_{1}<\frac{d_{2}}{\mu(1+\beta)}$ adalah

$$
\frac{d_{4}-\eta_{2} \beta}{\alpha(1+\beta)}<\eta_{1}<\frac{d_{2}}{\mu(1+\beta)}
$$

Kondisi ini membuktikan $y_{1}=y_{2}=y_{E_{1}}^{*}>0$, jika $\frac{d_{4}-\eta_{2} \beta}{\alpha(1+\beta)}<\eta_{1}<\frac{d_{2}}{\mu(1+\beta)}$, dan

$$
\alpha<\beta-(\beta+\mu) y_{E_{1}}^{*}
$$




$$
\begin{aligned}
\beta-(\beta+\mu) y_{E_{1}}^{*}-\alpha & >0 \\
\beta-\left(\alpha+(\beta+\mu) y_{E_{1}}^{*}\right) & >0 \\
\frac{\beta-\left(\alpha+(\beta+\mu) y_{E_{1}}^{*}\right)}{2(1+\beta)} & >0 \\
\Rightarrow x_{I} & >0
\end{aligned}
$$

Karena $y_{1}=y_{2}=y_{E_{1}}^{*}>0$ dan $x_{I}>0$. Terbukti titik kesetimbangan $E_{1} \in \mathbb{R}_{+}^{3}$, jika $\frac{d_{4}-\eta_{2} \beta}{\alpha(1+\beta)}<\eta_{1}<\frac{d_{2}}{\mu(1+\beta)}$ dan $\alpha<\beta-(\beta+\mu) y_{E_{1}}^{*}$.

Sehingga, terbukti persamaan (8) membuat ada satu titik kesetimbangan $E_{1} \in \mathbb{R}_{+}^{3}$, jika $D y_{E_{1}}^{*}=0$ dan terpenuhi kasus 1 atau kasus 2 .

Teorema 4.3 Titik kesetimbangan $E_{0}$ stabil atau stabil asimptotik lokal, jika $\beta<\frac{\alpha+\mu y_{E_{0}}^{*}}{1-y_{E_{0}}^{*}}$, $k_{0}>0, g_{1}>g_{2}$, dan $g_{3}>g_{4}$. Sebaliknya, jika syarat stabil tidak terpenuhi maka titik kesetimbangan $E_{0}$ tidak stabil untuk semua syarat stabil tidak terpenuhi, atau tidak stabil saddle untuk salah satu syarat stabil tidak terpenuhi.

\section{Bukti}

Akan ditunjukan $\lambda_{1}<0$ dan persamaan karakteristik $\lambda^{2}+\left(p_{1}-p_{2}\right) \lambda+\left(p_{3}-p_{4}\right)=0$ negatif atau memiliki bagian real negatif.

Untuk $\lambda_{1}<0$

$$
\begin{aligned}
\beta & <\frac{\alpha+\mu y_{E_{0}}^{*}}{1-\mu y_{E_{0}}^{*}} \\
\beta\left(1-\mu y_{E_{0}}^{*}\right) & <\alpha+\mu y_{E_{0}}^{*} \\
\beta\left(1-\mu y_{E_{0}}^{*}\right)-\left(\alpha+\mu y_{E_{0}}^{*}\right) & <0 \\
\Rightarrow \lambda_{1} & <0
\end{aligned}
$$

Dari matriks (4) diperoleh persamaan karakteristik

$$
\lambda^{2}+\left(p_{1}-p_{2}\right) \lambda+\left(p_{3}-p_{4}\right)=0
$$

Menurut uji kestabilan Routh-Hurwizt persamaan karakteristik (9) menjadi

$$
k_{0} \lambda^{2}+k_{1} \lambda+k_{2}=0
$$

dimana, $k_{0}=1, k_{1}=\left(g_{1}-g_{2}\right), k_{2}=\left(g_{3}-g_{4}\right)$.

Dengan demikian, matriks Hurwizt dari persamaan (10) berukuran $2 \times 2$, yang dapat dituliskan

$$
H_{2}=\left[\begin{array}{ll}
k_{1} & k_{3} \\
k_{0} & k_{2}
\end{array}\right]
$$

Berdasarkan kriteria Routh-Hurwizt, persamaan (10) memiliki akar-akar karakteristik real negatif atau memiliki bagian real negatif jika dan hanya jika

i). $k_{0}>0$

$$
\begin{aligned}
1 & >0 \\
\Rightarrow k_{1} & >0
\end{aligned}
$$


ii). $k_{1}>0$

iii). $k_{2}>0$

$$
\begin{aligned}
g_{1} & >g_{2} \\
g_{1}-g_{2} & >0 \\
\Rightarrow & k_{1}>0
\end{aligned}
$$

$$
\begin{aligned}
g_{3} & >g_{4} \\
g_{3}-g_{4} & >0 \\
\Rightarrow k_{2} & >0
\end{aligned}
$$

Karena $\lambda_{1}<0$ dan persamaan karakteristik (10) $k_{0}>0, k_{1}>0$, dan $k_{2}>0$ yang menyebabkan persamaan karakteristik (9) memiliki akar-akar karakteristik real negatif atau memiliki bagian real negatif, maka titik kesetimbangan $E_{0}$ stabil atau stabil asimptotik lokal. Jika syarat stabil diatas tidak terpunihi, maka titik kesetimbangan $E_{0}$, tidak stabil untuk semua syarat tidak terpunuhi, atau tidak stabil saddle untuk salah satu syarat tidak terpenuhi. $\square$

Teorema 4.4 Titik kesetimbangan $E_{1}$ stabil atau stabil asimptotik lokal, jika $k_{0}>0, p_{1}>$ $p_{2}, p_{3}>p_{4}, p_{5}>p_{6}$, dan $s_{1}>s_{2}$, dimana

$$
\begin{aligned}
& s_{1}=p_{1} p_{3}+p_{2} p_{4}+p_{6} \\
& s_{2}=p_{5}+p_{1} p_{4}+p_{2} p_{3}
\end{aligned}
$$

Sebaliknya, jika syarat stabil tidak terpenuhi maka titik kesetimbangan $E_{1}$ tidak stabil untuk semua syarat stabil tidak terpenuhi, atau tidak stabil saddle untuk salah satu syarat stabil tidak terpenuhi.

\section{Bukti}

Akan ditunjukan persamaan karakteristik (6) real negatif atau memiliki bagian real negatif. Menurut uji kestabilan Routh-Hurwizt persamaan (6) menjadi

$$
k_{0} \lambda^{3}+k_{1} \lambda^{2}+k_{2} \lambda+k_{3}=0
$$

dimana, $k_{0}=1, k_{1}=\left(p_{1}-p_{2}\right), k_{2}=\left(p_{3}-p_{4}\right)$, dan $k_{3}=\left(p_{5}-p_{6}\right)$.

Dengan demikian matriks Hurwizt dari persamaan (11) berukuran $3 \times 3$, yang dapat dituliskan

$$
H_{3}=\left[\begin{array}{ccc}
k_{1} & k_{3} & k_{5} \\
k_{0} & k_{2} & k_{4} \\
0 & k_{1} & k_{3}
\end{array}\right]
$$

Berdasarkan kriteria Routh-Hurwizt persamaan karakteristik (11) terdapat akar-akar karakteristik real negatif atau memiliki bagian real negatif jika dan hanya jika

i). $k_{0}>0$

$$
\begin{array}{r}
1>0 \\
\Rightarrow k_{1}>0
\end{array}
$$

ii). $k_{1}>0$

$$
\begin{aligned}
p_{1} & >p_{2} \\
p_{1}-p_{2} & >0 \\
\Rightarrow k_{1} & >0
\end{aligned}
$$

iii). $k_{2}>0$

$$
\begin{aligned}
p_{3} & >p_{4} \\
p_{3}-p_{4} & >0 \\
\Rightarrow k_{2} & >0
\end{aligned}
$$


iv). $k_{3}>0$

v). $k_{1} k_{2}-k_{0} k_{3}>0$

$$
\begin{aligned}
p_{5} & >p_{6} \\
p_{5}-p_{4} & >0 \\
\Rightarrow k_{3} & >0
\end{aligned}
$$

$$
\begin{aligned}
s_{1} & >s_{2} \\
p_{1} p_{3}+p_{2} p_{4}+p_{6} & >p_{5}+p_{1} p_{4}+p_{2} p_{3} \\
p_{1} p_{3}-p_{1} p_{4}+p_{2} p_{4}-p_{2} p_{3}+p_{6}-p_{5} & >0 \\
\left(p_{1}-p_{2}\right)\left(p_{3}-p_{4}\right)-\left(p_{5}-p_{6}\right) & >0 \\
\left(p_{1}-p_{2}\right)\left(p_{3}-p_{4}\right)-1 .\left(p_{5}-p_{6}\right) & >0 \\
k_{1} k_{2}-k_{0} k_{3} & >0
\end{aligned}
$$

Karena persamaan karakteristik (11) $k_{0}>0, k_{1}>0, k_{2}>0, k_{3}>0$, dan $k_{1} k_{2}-k_{0} k_{3}>0$, maka persamaan karakteristik (6) memiliki akar-akar karakteristik real negatif atau memiliki bagian real negatif. Sehingga, titik kesetimbangan $E_{1}$ stabil atau stabil asimptotik lokal. Jika syarat stabil diatas tidak terpenuhi, maka titik Kesetimbangan $E_{1}$ tidak stabil untuk semua syarat tidak terpenuhi, atau tidak stabil saddle untuk salah satu syarat stabil tidak terpenuhi. $\square$

\section{DAFTAR PUISTAKA}

[1] Berryman A. A., 1992. The Orgins and Evolution of Predator-Prey Theory, ESA Ecology Society of Amerika.

[2] Holling C. S., 1959. Some Characteristics of Simple Types of Predation and Parasitism. The Canadian Entomologist, The Canadian Entomologist, Vol. XCI, No.7.

[3] Anderson R. M., \& May R. M., 1986. The Invasion, Persistence and Spread of Infectious Diseases within Animal and Plant Communities: Discussion, Philosophical Transactions of The Royal Society B Biological Sciences, Vol.314, No.1.

[4] Chattopadhyay J., \& Bairagi N., 2001. Pelicans at Risk in Salton Sea, Ecological Modelling-ECOL MODEL, Vol. 136.

[5] Purnomo, A. S. Darti I., \& Suryanto A., 2017. "Dynamics od Eco-Epidemiological Model with Harvesting". AIP Conference Proceedings.

[6] Jha P.K., dan Ghorai S., 2017. "Stability of Prey-Predator Model with Holling Type Response Function and Selective Harvesting", Journal of Applied \& Computational Mathematics, Vol. 06.

[7] Edelstein-Keshet L., 2005. "Mathematical Models in Biology", SIAM, Canada.

[8] Perko L., 2001. "Differential Equations and Dynamical System ", Springer, New York. 